\title{
Art and science: Where numerology and mathematics touch the lung
}

\author{
S MARSH TENNEY MD \\ Dartmouth Medical School, Lebanon, New Hampshire, United States
}

SM TENNEY. Art and science: Where numerology and mathematics touch the lung. Can Respir J $1994 ; 1(4): 241-247$.

Mathematical analysis in the physical sciences has a long history that feveals not only a rich harvest of fundamental insights but also leads to at wonderment at the intrinsically formal beauly in nature. Rigorous analysis of form and function in the hiological sciences has been a more recent innovation, but introduction of the principles of similarity, scaling, fractal geometry. harmony and proportion has broadened our perspective. The lung provides an apt example to illustrate the usefulness of this kind of thinking.

Key Words: Allometw: Fratals. Lung structure-funtion relations, Scaling

\section{L'Art et la science : Où la numérologie et les mathématiques concernent le poumon}

RÉSUMÉ : La analyse mathématique dans les sciences physiques possède unc longue histoire qui révèle non seule ment une yuantité considérable d'intuitions fondamentales, mais yui incite alussi a sétonner de la beauté formelle inhérente à la nallure. I, analysc rigoureuse de la forme clu de la fonction dans les sciences biologiques est d'innovation plus récente, mais l'introduction des principes de similarité, de mise à l'échelle, de géométrie fractale, d'harmonie et de proportion a élargi nos horizons. Le poumon fournit un exemple pertinent pour illustrer l'utilité de ce type de raisonnement.
A RT AND SCIENCE: THE ONE: A CREATIVE ENDEAV()UR. THI: other more concerned with discovery. but both have long and strong lies to numbers. And both embody the concept of beauty. In the arts it is treated in the theory of esthetics; in the sciences its purest expression is a mathematically revealed truth. The poetic axiom "truth is beauty and beauty is truth" acknowledges that the two are inseparable. The great mathematician, Hermann Weyl, once said, "My work always tried 10 unite the truc with the beatuliful; but when I had lo choose one or the other, I usually chose the beautiful." Whether or not that admission is regarded as surprising depends on the depth of appreciation of how these quilities have been appraised by humans in their conception of the externat world. It helps to remember that, in the historical development of the sciences, their beginnings almost always were based on metaphysical beliefs, usually with an esoteric value - alchemy before chemistry, astrology bofore astronomy. Further. it is important 10 keep in mind the motivation of primitive scientist and antist alike 10 reveal God, "the good and wise Artisan of all things". In his letter (1595) to Maestlin, Kepler wrote, "I strive, therefore, for the glory of God, who wants to be recognized from the book of 
Natture." The underlying question was, how is this cosmic architecture represented"? and the answer was, that it could be found in an esthetic of number and geonctric form. That viewpoint can be traced to the shadowy figure of Pythagoras living in the 5 th century $\mathrm{BC}$. quite possibly the most influential man who ever lived.

It is traditional to cite the Timacus of Plato lor its mathematical view of esthetics, stressing simplicity and symnetry ats essential features. The early attitude towards art as excelling only to the extent that it recreated natural form was based on Plato's teaching, but he has clearly drawn on the Pythagorean prescription: form and number must be in harnony. lndeed. Pythagorals believed "all things are number", and by this number mysticism, he meant not only that they had a saered character but also a physical reality. Pursuit of the underlying harmonies in nature constituted a drive towards science, but rationality and the discovery of order did not cradicate their mystical significance. God remained the great geometer.

No books epitomize more comprehensively a geometric theory of the cosmos than Johannes Kepler's Harmonices Mundi (1619), a work in five volumes that encompasses musical theorems, structure of the solar system. mathematical proofs, a description of the rhombic dodecahedron and its significance for the structure of a honcycomb, and much more.

The guiding principle of Kepler's synthesis can be anticipated in a quotation from Proclus that he places on the title page of Hormonices Mundi. It reads:

\section{Mathematics also makes contributions of the very greatest value to the study of Nature. It reveals the orderliness of the ratios according to which the Universe is constracted and the proposition that binds things together in the cosmos. It exhibits the simple and primat causal elements as everywhere clinging fast one to cinother in stmmetry and equality. the properties through which the whole heaven was perfected when it took upen itself the propertices appropriate to its particular region.}

Compare this viewpoint written in the 5 th century with that of a famous contemporary physicist (VF Weisskopl):

\section{The ideal element in mature consists in the fact that mathematical lans, which are kass's of our own thoughth. really leold in nature. And that deep amazeneste which we often feel over the inne' order of nature is conneeted above all with the circumstance that, as in the casc of crystels, we have already recognized the effects of this 'mathe'matics of nature' long before ont own mathematical knowledge was sufficienty developed ter understand its ne'cessity.}

These quotes reveal at eontinuity of thinking about and recognition of an inherent esthetic quality in the mathematics of nature that, in Kepler's understanding, reached its highest form in music. Musical relations could be derived from geometry, and harmony could he defined on a simple integral ratio. It was not simply that the good. the true and the beautiful were natural correlates of harmony, but that the physical reality of the lengths of chords on a lyre were visible manifestations of these underlying qualities. Kepler lound musical ratios among the velocities of the plancts, and even Newton wrote of the numerical relationship of the seven colours to the seven chords of the nusical octave.

Although the greater emphasis wals given to finding a numerological code for all things in the physical universe, the significance of harmonious ratios for human liorm and physiology was not entirely neglected. Particularly, as man was seen as a microcosm. or in the words of Leonardo da Vinci, "a model of the world", the traditions of Hermetic philosophy became bound up with the mystery of occult numbers, and their source can often be traced to Kepler"s cosmology. Nonetheless, Kepler's works are also genuincly scientific in the modern sense and so can be regarded as representing a transitional stage in the history of science. However. if the works of the 17 th and 18 th century iatromathematicians and iatromechanists are ignored because of their limited scope, it can be seen that a long time elapsed before a truly definitive classic in biological science appeared, a work that would establish, with a wealth of informattion and rigorous analysis, the fact that the laws of physical science could be applied to living organisms. D'Arcy Wentworth Thonpson's On Growth and Form was published in 1917, and an expanded edition appeared in 1942 (1). The encyclopedic character of the book is matched by a masterful literary style that makes the work as enjoyable as it is informative. It is no surprise that the author is no less remarkable than the book he wrote.

D'Arcy Thompson was born in 1860) in Edinburgh, an only child whose gilis in scholarship and the classics can be traced to his father. and those in science, to his mother. In his portrait of Thompson (in The Alt of the Soluble') Peter Medawar (2) wrote:

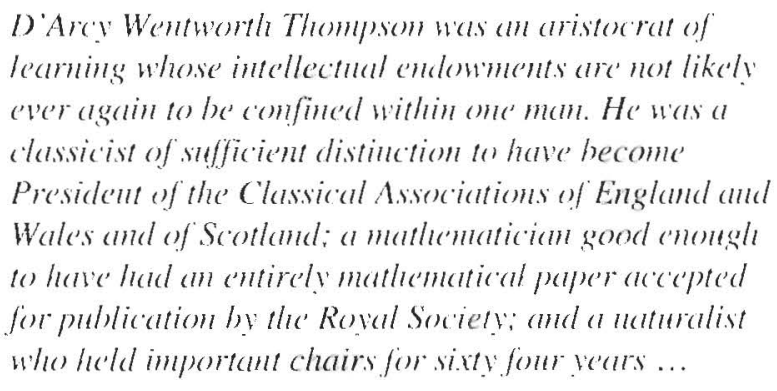

His many books ate still quoted. hut there is no doubt that On Growth and Form was the most influential. It set forth mechanical correlates of biological concepts, the result locing that form became a stress-strain diagram. The revolutionary nature of Thompson's way of thinking (again, expressed by Medawar) was that:

His conception of structure weas of molecular as weth as of merety' visible dime'nsions, his thought travelling without impediment across the doren orders of magnitude that separate the two.

Thompson's inatomy recognized "no fronticr between biological and chemical form". However, when asked to 
prepare a preface for his work. Thompson replied that that really ought to be unnecessaty, beciuse the whole book was nothing more than a preface!

In the composition of this modern classic Thompson established its continuity with the past. Consulting the index one finds that Kepler is referred to ninc times; Borelli, eight times; Pythagoras, four. Without in any way succumbing to the lure of occult significance in numbers, D’Arcy Thompson was not loath to recognize the insights and landmark contributions of great thinkers who did; in his own unique way his major work, now more than 70 years old still stimulates and still provides a rich resouree of ideas wating to be harvested. The "principle of similitude" is one that Thompson developed extensively.

\section{SIMILARITY, ALLOMETRY, SCALING}

A basic problem in biology is that of body size, and in living organisms there is an astonishing range: the ratio of largest to smallest is $10^{21}$. For land mammals - elephant to shrew - it is $10^{\circ}$, but function remains similar. The architect and the engineer who design bridges or buildings of increasing size are familiar with the problem of scaling, viz, the consequences of change in sis. There are predictable limits, and there are constraints for any given size. The biologist confronts the problem from the opposite direction: the living form already exists. and the challenge for the observer is to analyze the inherent design on the premise that it was necessary for survival. The scale most convenient for a study of animals is their mass (M). The assumption that mass and volume are equivalent is usually adopted, and the relationships of linear dimensions (length, L) are examined. If the dimensions of a small structure are found all to be multiplied by the same factor in a large structure they are said to maintain geometric similarity. That is, they ate ismmctrice In geometric similarity volumes are proportional to the cube of linear dimension and areas are proportional to the square of linear dimension $\left(\mathrm{L}^{2}\right)$. Living systems are rarely isometric; more often what is found is a distortion of shape as a function of size, and this is termed allometry. Galileo noted that the bones of large animals were proportionally thicker than those of small animals in accord with a principle well known to engineers when calculating the necessary diancker of supporting columns. The essential requirement for a structure in a living or nonliving system is to serve well the function for which it was designed, but functional similitude rarely follows geometric similitude. Thompson credits Herbert Spencer as the first to show the usefulness of similarity analysis in biology, but it was D'Arcy Thompson who explored the rich varicly of applications in biology ranging over explanations of why the ostrich camnot My, why the bee's wing vibrates faster than a birl's and why a flea can jump as high as a human. Lord Rayleigh. in response to a letter from Thompson published in Nuture in 1915, gently chiding him for his neglect of mentioning the use of the principle of similitude, wrote an elocpuent defence setting forth his own high opinion of the value of thinking about "dynamical similarity' (the inlluence of scalc upon physical phenomena):

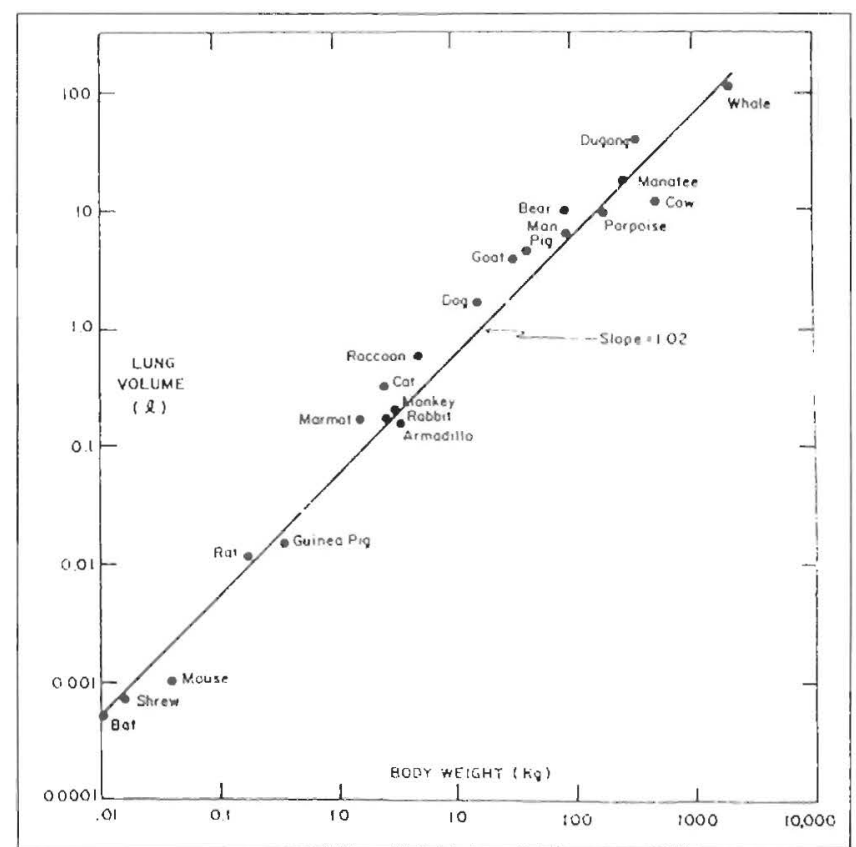

Figure 1) Logarithmic plot of tung wolume wetated to body mass in mammals, demonstrating a slope of l.(12) (t)

It often happens that simple rectsoming formeted upom this principle tells as nearty all that is to be leathed from eren a sucessiful mathematical intestigation and in the numerous cases where such an investigation is beyold ner powers. the princtule gives us information of the utmost importance.

Julian Huxlcy (3) introduced in 1927 the allometric equaltion

$$
Y=a M^{b}
$$

in which $Y$ may he some stretetural, saly. Iung volume, of functional licature. say, respiratory frequency. which is to be examined over a range ol body sizes, expressed as boly mass. $M$; $a$ is a coefficicnt; and the exponent $b$ can be compared with the expected dimension of the structure. Jrom the principle of geometric similarity, linear dimensions, such ats alveolar diameter. ought to vary as $M^{1 / 3}$ and $L^{1}$; areas, such as alveolocapillary surface area, as $M^{2 / 3}$ and $L^{2} ;$ and volumes, such as lung volume, as $M^{1}$ and $L^{3}$. The greatest interest arises when the dimension of the structure in terms of the exponent differs from the simple prediction because the investigator is then stimulated to discover the functional necessity for the distortion. For example, the lengths of pendulums of clocks do not increase in proportion to other lengths. because the period of a pendulum depends not on its length but the square root of its length. In the examples cited only Iung volume has the expected exponent (Figure I) (4). which should cause us to reflect on the use of conventional prediclion equations expressing lung volumes as a lincar function of height (ic, as $\mathrm{I}_{-}{ }^{\prime}$ ) rather than $\mathrm{L}^{3}$.

Of all the structural and functional variables in respiratory physiology subjected to allometric analysis, the one most 


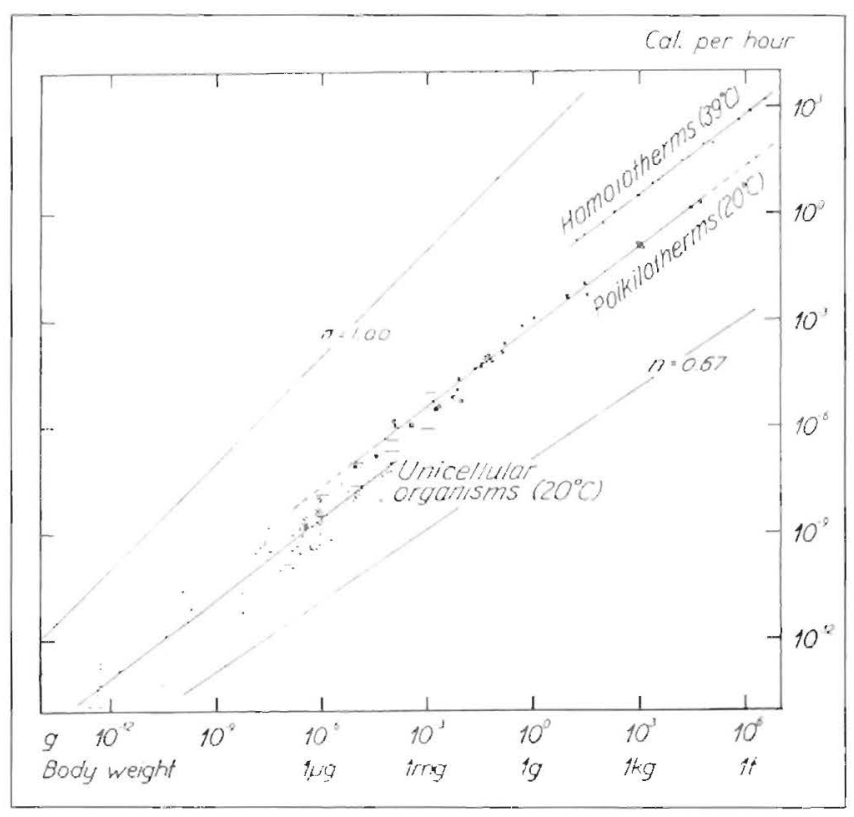

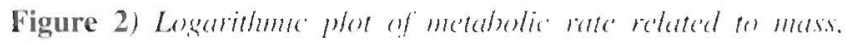
derived from published studies of invertebues. cold and warm-

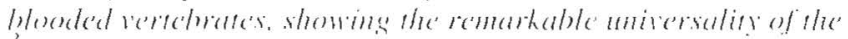
$\frac{3}{4}$ expenent (5)

extensively studied is oxygen uptake rate. Oxygen enters the organism by diflusion across a surface, and, therefore, the vilue ought reasonably to be predictable as varying with hody size as $M^{2 / 3}$; this would be consistent with the conventional expression of basal metabolic rate as a function of surlace area $\left(\mathrm{BMR} / \mathrm{m}^{2}\right)$. The experimental findings, howcver, from the smallest to the largest organisms, both warmand cold-blooded, are that resting oxygen uptake rate valrics as $M^{3 / 4}$ (Figure 2) (5). For maximal oxygen uptake (VO $\mathrm{V}_{\text {mix }}$ ). conventionally scaled as $\mathrm{M}^{1}$ in $\mathrm{VO}_{2 \mathrm{max}} / \mathrm{kg}$, the exponent is again less than $1(6)$. The exponent, $\frac{3}{4}$, suggests a "compromise' between metabolic processes remaining constant, per unit weight (the simplest biochenical assumption) and, therclore, increasing in proportion to body weight. ic, $M^{l}$. and being limited by diffusing surface areal or, in the case of exercise muscle cross-sectional areal, predicted to increase as $M^{2 / 3}$. Conjectures like "compronisc" carry no useful meaning, and the real explanation remains clusive. But the question is important and illustrative of the usefulness of allometric analysis to reveil some universal principle, even though it fails to provide any mechanistic explanation.

\section{FRACTAL GEOMETRY, FRACTAL DIMENSIONS}

D'Arcy Thompson's life ended before the new mathematics of fractal geometry were developed, but it is a safe prediction that, had he lived to see the profound insights fractal geometry introduces for the study of natural forms, he would have been delighted. Benoit Mandelbrot's book, The Iructal Geometry of Nature (7), has had a major impact on both science and art. If, as Plato and Aristotle insisted, the line arts imitate nature, then the geometric abstraction had to fall baick on a resemblance more than an imitation, because the real forms in nature could only be approximated by classical mathematics, which is limited to idcals. An orange is not a sphere, at volcanic mountain is not at cone. Real forms have bumps and atll sorts of irregularities that make them complex and impossible to analyze by Euclidean geometry. What would be the mathematical description of a cloud or for that matter, of the human brain? Fractal geomctry comes to the rescuc. Its origins (but not called by the name: Mandelbrot coined the term) reach batek to troublesome constructions. well known to many mathematicians in the 19th century, called monster curves - curves that were continuous. but whose generating function was not differentiable. They had no unique tangent at any one point, and their length could not be measured. Their dimension wals only an effective dimension', and it had a subjective basis. Consider Mandelbrot's example of at ball of twine: At a great distance it looks like a point (dimension $=0)$; closer up it looks like a sphere (dimension $=3$ ), still closer it is seen to be a mass of threads (dimension = 1), and closer stifl, each thread is seen to be a column (dimension $=3$ ); at the level where fibres alre seen, they are interpreted as lines (dimension - 1): and it the atomic level, the appearance again is ol' points (dimension = ()). However, there are ill-defined /ones of transition from one classical Euclidean dimension to another, and these are fractal zones. There, the dimension will not be an integer.

Most fractals are found to be invartiant under transformations of scale; they are self-similar under ordinary geometric similarity, and an enlargement of a smiall portion resembles the whole structure. A landmark paper that clearly presented the problems of a fractal curve was published in 1961 in an obscure, and for the subject, inappropriate, periodical (Gen'ral Systems Yearbook) (8). The author. Lewis Fry Richardson, was an ingenious eccentric with a doctorate in prychology, known for his highly origimal contributions to weather forecasting, a Quaker who wrote extensively on war, and a min with deep mathematical insights. I Iis seminal, but long neglected, work on fractals dealt with their peculiar properties in regard to the problems of mensuration and dimension. Richardson's question was deceptively simple: How long is the coastline of Britain? The answer he gave was that it depends on the length of the measuring stick used. Clearly, a metre stick would miss the perimeters of a great many indentations that would be included if a centimetre stick were used, and a millimetre stick would add still more. In fict, resolution to atomic structure is imaginable; theoretically, there is no reason to stop there. The conclusion must be: ils the measuring stick gets shorter the length of the coastline increases indefinitely, but the limit is meaningless. In mathematical terms a continuous series is differentiable because it can be split into an infinite number of straight lines; but a nondifferentiable series, even though continuous, cannot be resolved in this way, because cakch successive split merely reveals still more roughness. To solve the practical problem of measurement an arbitrary decision has to be made regarding the measuring device.

How can one arrive at a dimension for al structure like a coastline? The answer is that it will depend on the degree of irregularity. Imagine pencilled wiggles on a plane piece of 
paper. So long an lhey are seen as lines their dimension will be 1 , but as the paper begins to be filled, the scribbled lines begin to look like a plane area, and the dimension would be 2. The real dimension must lie somewhic between 1 and 2. For a crumpled surface the dimension must lie between 2 and 3. depending on the extent to which it departs from smooth to crumpled. The liactal dimension (also called the HausdorffBesicovich function) reflects the degree of roughness of spatial data; it is a measure of complexity. The solution of the problems of measurement and dimension is expressed in a simple equation.

It can be shown that a length, $L$, measured with a stick of length $\varepsilon$ (relative 10 a unit stick) will be

$$
L(\varepsilon)=\varepsilon^{1-D}
$$

where $D$ is the fractal dimension. $D$ resolves the conceptual problem of length. Although all coastlines must be of infinite length, the value of $D$ depends on the coastline chosen. And, by choosing a value of $\varepsilon$, the observer has determined the particular partial reality that will be revealed. Humans thus set themselves above naturc - an interesting instance of anthropocentrism.

Fractal curves are generated by recursive procedures that derive each new generation by repeating some specific operation on the preceding generation. The idea of dimension can be illustrated by the following. If a line is stretched to twice its length, it can be cut in half to produce two copies of the original. The dimension of the line is the exponent of 2 (the magnifying factor) that will give the number of copies $=2$. The exponent (dimension) must be $\log _{2} 2=1$. Likewise, if the sides of a square are doubled, the exponent (dimension) will be $\log _{2} 4=2$. And for a cube, the dimension is $\log _{2} 8=3$. If these integer multipliers are replaced by some other - say, one that increases the length of a line repeatedly by a factor of $\frac{4}{3}-$ the limiting curve will have a dimension (fractal) that is $\log _{3} 4=1.26 \ldots$ The fractal dimension indicates that the curvo is more complex than a line; it partially fills a plane space, but it has not yet filled it; otherwise, it would be an area and have dimension $=2$. The limiting curve fulfils the criteria for a fractal, and of the hundreds of computer-generated fractal curves almost all have an astonishing, abstract beauty. The connection of these curves with phenomena like turbulence and Brownian motion is not intuitively obvious, but the sense of wonderment was expressed by Mandelbrot: "... fractal geometry reveals that some of the most austerely formal chapters of mathematics had a hidden face, a world of pure plastic beauty unsuspected until now."

The significance of liactal geometry for the form and function of the lung has not been neglected (9). The design of the bronchial tree is that of a bifurcating self-similar structure with progressive diminution of tube diameter in each generation. The system functions with minimum entropy production (10). The successive diameters in the bronchial system appear to be fractal, but it is necessary that this space-filling system, which is designed to conduct gas to and from alveoli. must reach some limit in the recursion process - a limit undoubtedly set by sonk minimal volume of uninvaded space (atveoli) necessary to maintian gas exchange. This illustrates the fact that no real system is infinitely fractil.

The respiratory surface of the lung is fractal and may be regarded as tending towards a maximal surface area in a minimal volume; in fish the oxygen-absorbing organ can be approximated by fractal lines. The characteristics of a fractal

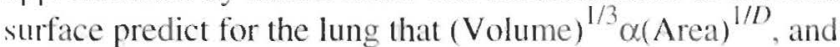
that $D$ will be greater than 2 and could approach 3 . Further, the measured alveolar area will, like measuring the length of a coastline, be dependent on the measuring instrument. Indeed, alveolar area measured with a light microscope is 80 $\mathrm{m}^{2}$, but with an electron microscope, it is $140 \mathrm{~m}^{2}$, and $D=2.17$ (II). Insofar as gas exchange is concerned, irregularity of the alveolar surface membrane is of little consequence since alveoli have a liquid lining layer, but for water and solute exchange there may be considerable importance.

\section{SIZE RATIOS AND LOG-NORMAL DISTRIBUTIONS}

In 1959 Evelyn Hutchinson, in a paper entitled "Homage to Santa Rosaliat. or why are there so many kinds of animals?" (12), observed that similar species existing in a similar ecological environment tended to be distinguished by a size ratio of about 1.3. The significance of the value 1.3 became incorporated in ecological theory as representing the size difference necessary for coexistence, ie, this was a limit below which competition became too great. The community would be forced to settle out into a distribution of species size ratios of 1.3 for stable survival; and the aspect of size might be whole body mass, or beak length of birds, or any structural feature that would prevent two species existing in identical ways. This came to be known as the competitive exclusion principle, and values around 1.3 were called the Hutchinson 'constant', or the Hutchinsonian ratio.

Many data filled the literature confirming the widespread prevalence of size ratios around 1.3 in nature, and the number began to take on a certain mystical significance. When it was discovered that a similar ratio could be found in the world of inanimate objects (13) its unique significance for community survival of living things vanished. The ubiquitous presence of the 1.3 ratio rule was almost comically demonstrated. II could be shown for lengths of an ensemble of recorders, for diameters of bicycle wheels and skillets, for cookie cutters and animal ligurines. The last example is farthest removed from any utilitarian explanation and might be thought of as some guiding impulse in artistic expression. Maiorana (14) has postulated that "an explanation for these observations may have to do with our perceptual abilities, a cause that may be applicable to (and perhaps derived from) the natural world".

The underlying message appears, however, to bo much simpler. The Hutchinsonian ratio is nothing more than an artifact of log-normal distributions (1.5). The usual assumption adopted by experimenters is that their data are distributed in a normal error curve, and that statistical inferences can then be made with the satisfaction of knowing how a normal error curve arises. The central limit theorem of statistics says that "the addition of a large number of small independent 
random variables yiclds a quantity whose distribution tends towards the normat distribution". In many instances, the requirements for the applicability of the central limit theorem are not met, and most often it is because the sourees of data are not the result of simple additive combinations but instead are based on muliplicative combinations. In that instance, the datat can be made to fit a normal distribution curve if the logarithms of the datat are plotted. The distribution is then log-normal, and it is apparent that there are many more ways in which a log-nomal distribution can arise in biology than is the case for normal distribution. It is unfortunate that demonstrating a good log-nomal fit in no way is helpful in deducing the interactive processes that must have been rosponsible, but siet ratios in the range 1.2 to 2.0 will result, given only that simes atre log-normally distributed, and that the standard deviation is less that $!$

Respiratory physiologists have not been prone to make much use of log-normal distributions, but it is noteworthy that flemamn Rahn, in his 1949 paper on ventilation-hlood flow relationships (16). adopted a log-normal plot ats simplest for the ventilation:perfusion distribution ratios throughout the lung. This contention has stood the test of time and experimentation (17).

\section{THE ‘DIVINE PROPORTION’ AND FIBONACCI SCALING}

lrom the time of Pythagoras there has been a fiscination with at ratio that seems to be associated with esthetic appreciation and has unusual properties that have heen explored in the theory of numbers. Classicull references speak of the 'Golden Section' of a line, which is made als follows (Figure 3).

If a line of length $A B$ is cut at $C$ in such a waly that $A B / A C$ $=A C / C B$. the consequences are of considerable interest. The easiest way to see this is to let the segment $A C$ be $x$, and the segment $C B$ bo unity; then the ratios result in the quadratic eytation:

$$
x^{2}-x-1=0
$$

whose roots anc

$$
\frac{1}{2}(1+5) \text { and } \frac{1}{2}(1-5), \text { or } 1.61803, \text { and }-0.61803
$$

The first number is usually called $\phi$, and the second, $\phi^{\prime}$. The remarkable properties alluded to are now apparent:

$$
\phi^{\prime}=-\frac{1}{\phi} \text { and therefore, } \phi \phi^{\prime}=-1
$$

$\phi$ is the only known number which. if diminished by unity, becomes its own reciprocal. ic,

$$
\phi-1=\frac{1}{\phi}
$$

therefore, $\phi^{2}-\phi-1=0$. and $\phi+\phi^{\prime}=1$.

The significance of the ratio that defines a Golden Section in natural and man-made designs was analyzed in detail by the Milanese friat and mathematician Luca Pacioli in a book

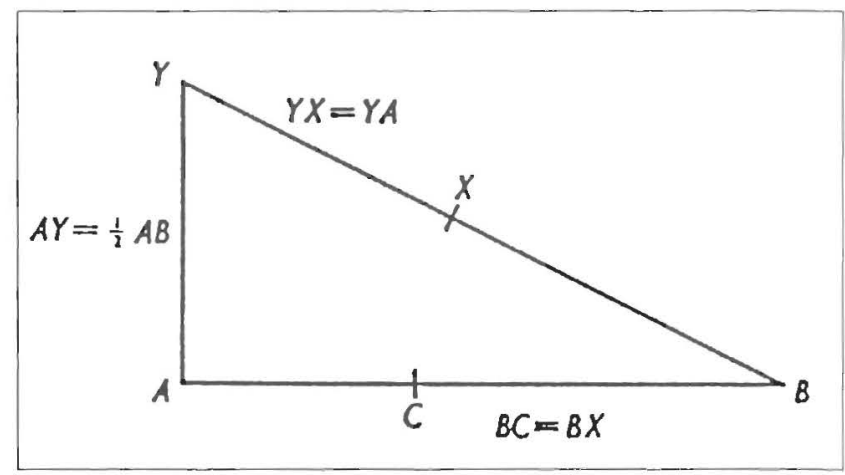

Figure 3) The 'Golden S'ention'

that has become a classic in architecture, Do Divina Proportione $(1509)$. It has the added distinction of carrying illustrattions by his lriend Leonardo dat Vinci, who perfected at three-dimensional perception for the many geometric lisures.

The number $\phi$ appears as the limit of an inlinite series that is associated with the name Fibonacei. Leonardo of Pisa was nicknamed with a conjugation of Filius Bonacei (son of the buflilo), Fi Bonateci. The Fibonacci scries is (), 1, 1, 2, 3, 5 , 8. 13,21, ... Each number is merely the sum of its two predecessors, or

$$
\lim _{n \rightarrow \infty} \frac{U_{n}+1}{U_{n}} \rightarrow 0
$$

It is the simplest of all continued fractions, and the suceessive ratios of the mumbers $\left(\frac{8}{13}, \frac{13}{21}\right.$. Cle) rapidly approalch the Golden Section (0.618). The series and the Golden Section appear repeatedly in mature, and no example is mor spectacular than that of the chambered nautilus. Each new chamber in the growing shell is at self-similar replicat of the preceding chamber. The principle of this construction is batsed on the Golden Section of a rectangle made in sticecesive steps to reach a limiting rectangle, which is the pole of an equiangular spiral the spira mirabilis of Keples; a curve that so fascinated Jacques Bernoulli that he had a logarithmic spiral engraved on his tombstone with the inseription. "Eadam mutara resurgo"). The length of the sides of the squares in the construction is a Fibonacei sories, and hence. any two segments are different in size but not in shape.

Even in the times of Euclid, to divide a line inte ant "extreme and mean ratio" as a first step in the construction of a pentagon was well recognized, and from there it was possible to proceed to the Pythagorean symbol of the cosmos, the regular dodecahedron.

In nature, the beatutiful symmetry of the bee's honeycomb has been an inspiration dating from ancient Greece to the present day. The hexagonal array of cells is a well known feature of close packing, but it was also recognized as an architecture that wals most economical in the use of wax. There were those who ascribed this uptimal property to a divine guidance of bees sinee they could not be supposed (1) have highly developed mathematical skilts. Such opinions invited D'Arcy Thompson's scorn. His comment was that the 
"beautiful regularity" was due only 10 "some automatic play of physical forces". More recently the Hungarian mathematician Fejes-Tóth. in a paper entitled, "What the bees know and what the bees don't know" (18) has demonstrated that the bottom of the bee's cell is not constructed in the most economical way, so we are left with an example of good, but not perfect, design.

The discovery that the irregular branching pattern of the human bronchial tree can be described by al scale of Fibonacci numbers wals made in 1985 by Goldberger et al (19). This growth pattern of self-similarity is like that of the sneezewort on which a new branch springs from each axil, and more branches grow from the new branch in such a way that if the old and new are added a Fibonacei sequence is obtained. These diverse examples illustrate a common theme of fractal self-similarity and Fibonacei proportionality to give structures of great beatuty on the one hand, and probably serve to minimize constructional error on the other, as D'Arcy Thompson pointed out. The mechinisms that determine morphogenesis according to these principles remain to be discovered, but extending from the proportions of the Parthenon to proportions in the human body, the number $\phi$ is a persistent and tantalizing presence.

Esthetes are not likely to look to the lung as the most beautiful structure in nature, nor are pulmonologists inclined to romanticize pulmonary structure and function: yet, the design of the lung reveals all of the classical ingredients of beauty and of purpose optimally achieved. Recollecting the

\section{REFERENCES}

1. Thompson D'A W. On Growh and Form, 2nd edn. New York: Cambridge University Press, 1942.

2. Medawar P. The Art of the Soluble. London: Methuen, 1967.

3. Huxley JS. On the relation between egg-weight and body-weight in birds. J Linnaen Soc Zoo! 1927:36:457-66.

4. Tenney SM, Remmers J. Comparative quantitative morphology of the mammalian lung; diffusing area. Nature 1963;197:54-6.

5. Hemmingsen AM. Energy metabolism as related to body size and respiratory surfaces, and its evolution. Reports of the Steno Memorial Hospital and the Nordisk

Insulinlaboratorium 1960;9(Pt 2):7-110.

6. Taylor CR, Maloiy GMO, et al. Design of the mammatian respiratory system. III. Scaling maximum aerobic capacity to body mass: wild and domestic animals. Respir Physiol 1981;44:25-37.

7. Mandelbrot BB. The Fractal Geonnely of Nature. San Francisco: Freeman, 1982

8. Richardson LF. The problem of contiguity: an appendix of statistics of deadly quarrels. General Systems Yearbook 1961;6:139-87.

9. McNamee JE. Fractal perspectives in pulmonary physiology. J Appl Physiol 1991;71:1-8.

10. Wilson TA. Design of the bronchial tree. Nature characteristics of similarily, scaling, complexity inherent in its fractal geometry, harmony and proportion inherent in Fibonacci scaling, the temptation to see how the lung stands up under the reguirements of the "aesthetic formula' is irresistible. George D Birkhoff, a prominent American mathemattician of this century, proposed in his book Aesthetic Measure (1933) that if the esthetic measure, $M$, of any class of objects, is "any quantitative index of their comparable aesthetic effectiveness", then it will depend on the ratio of complexity, $C$, of the object and the property of harmony, symmetry, and order, $O$. Hence,

$$
M=f(O / C)
$$

and the esthetic experience is seen to be measured "by the density of order relations in the aesthetic object". On these grounds, the lung must receive a favourable judgment; its architecture warrants acclamation.

Since the more profound understanding of the mathematical principles that determine structure from the molecular to the organismic level remains to be discovered, these remarks appropriately close with a guote from the great 17 th century Neapolitan mathematician and biologist, Giovanni Borelli, who wrote for the introduction of his De motu amimalium:

But so great a machinery of vessels and organs of the lung must have been instituted for some grand purpose: and that we shall try to expound if possible, though we shall stammer as we go along.

1967;213:668-9

11. Wiebel ER. The pathways for oxygen. Cambridge: Harvard University Press, 1984.

20. Birkhoff GD. Aesthetic Measure. Cambridge: Harvard University Press, 1933.

12. Hutchinson GE. Homage to Santa Rosalia, or Why are there so many kinds of animals? Am Naturalist 1959;93:145-59.

13. Horn HS, May RM. Limits to similarity among coexisting competitors. Nature 1977;270:660-6.

14. Maiorana VC. An explanation of ecological and developmental constants. Nature 1978;273:375-7.

15. Koch AL. The logarithm in biology. 1. Mechanisms generating Iog-normal distribution exactly. J Theor Biol 1966;12:276-90.

16. Rahn $\mathrm{H}$. A concept of mean alveolar air and the ventilationbloodflow relationships during pulmonary gas exchange. Am J Physiol 1949;158:21-30.

17. West JB, Wagner PD. Ventilation-Perfusion relationships. In: JB West, et al, eds. The Lung; Scientific Foundations. New York: Raven Press, 1991.

18. Fejes-Tóth L. What the bees know and what the bees don`t know. Bull Am Math Soc 1964:70:468-81

19. Goldherger AL, West JB, Dresselhaus 'T, Bhargava V. Bronchial asymmetry and Fibonacci scaling. Experiential 1985:41:1537-8. 


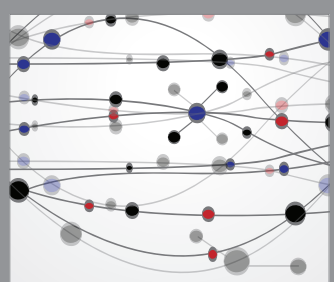

The Scientific World Journal
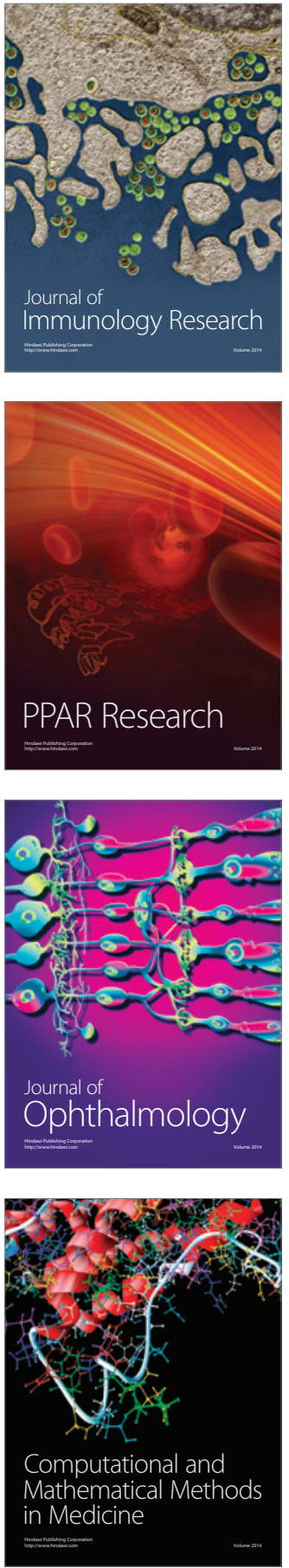

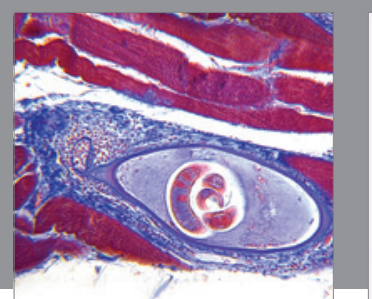

Gastroenterology Research and Practice

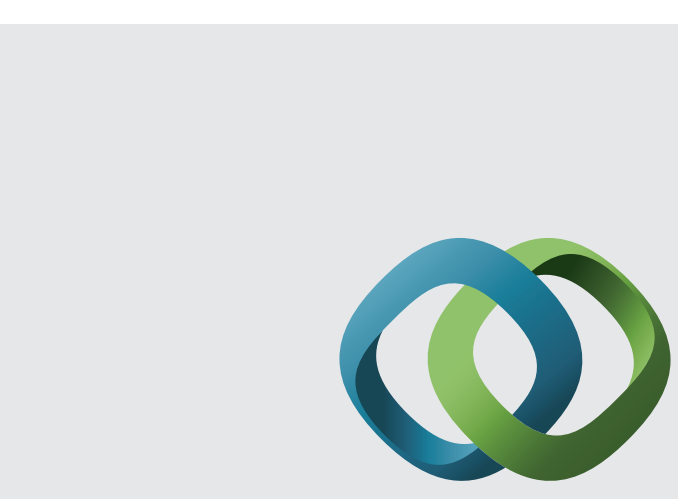

\section{Hindawi}

Submit your manuscripts at

http://www.hindawi.com
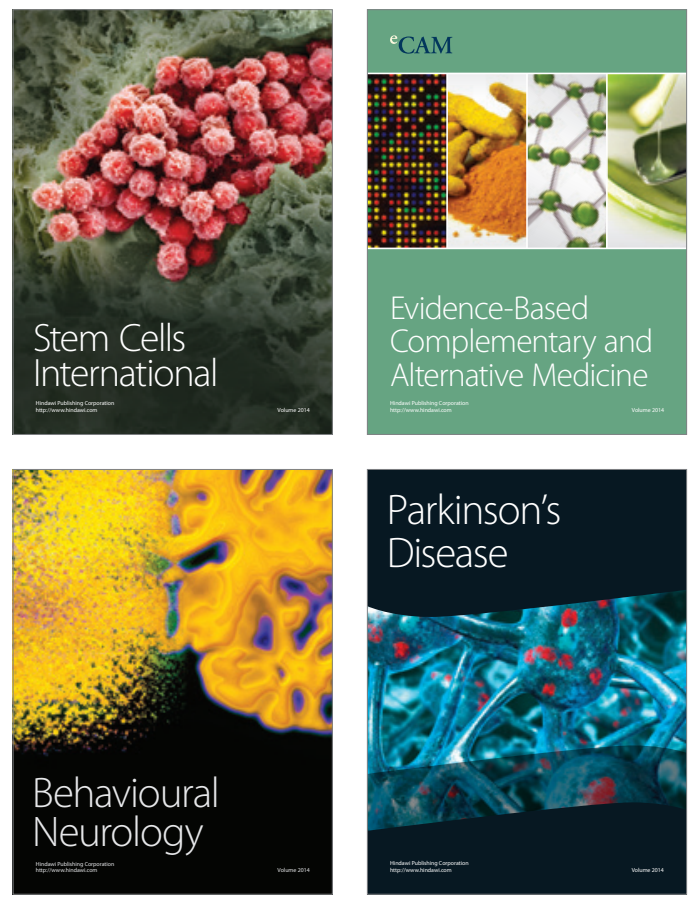
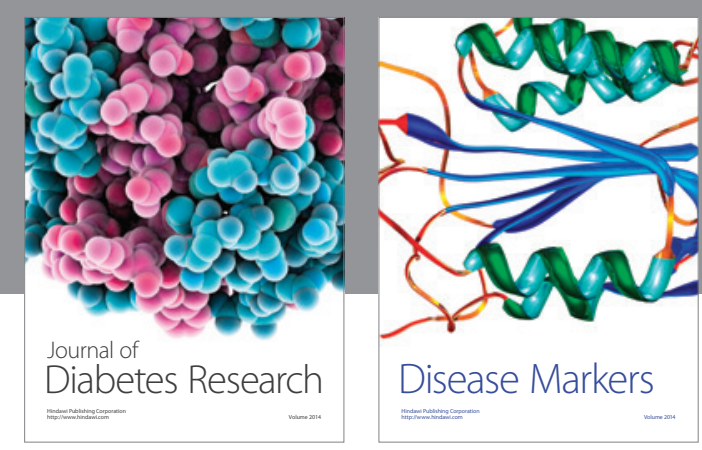

Disease Markers
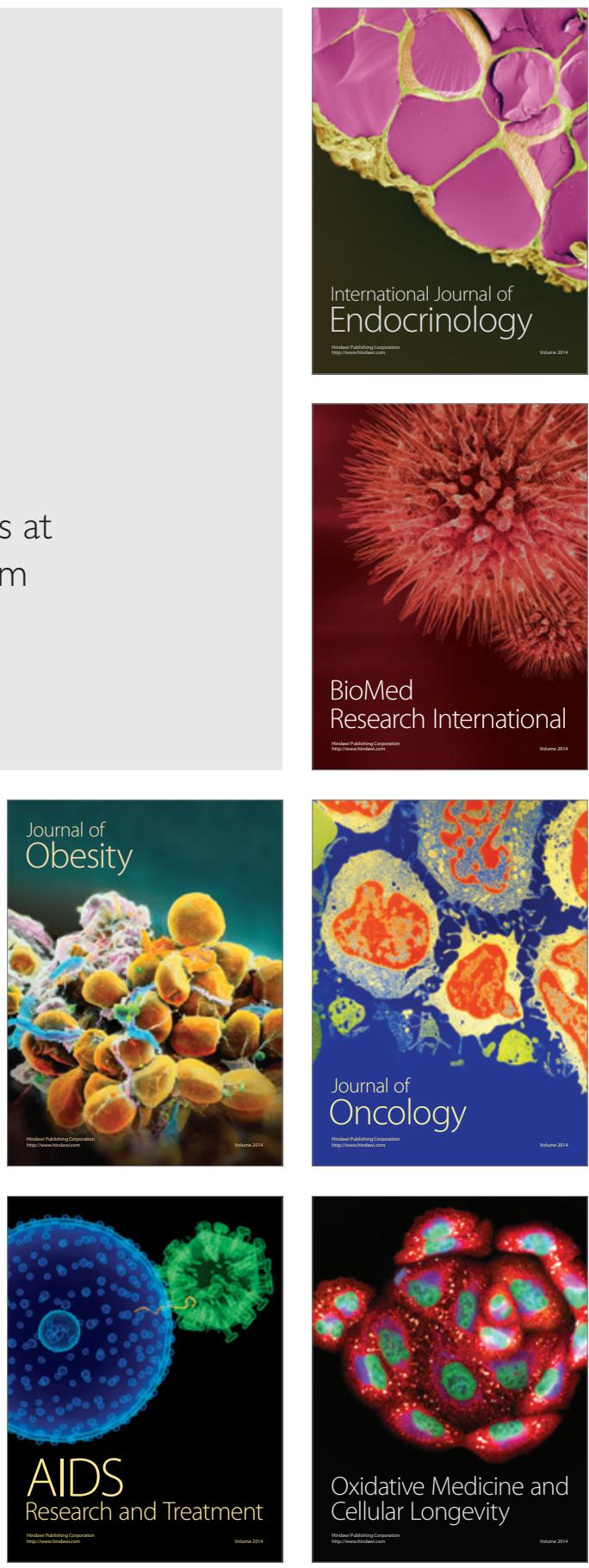